5-1-2017

\title{
Uncertainty in Financial Markets and Business Cycles
}

\author{
Seçil Yildirim-Karaman \\ Istanbul Kemerburgaz University, secil.yildirim@kemerburgaz.edu.tr
}

Follow this and additional works at: https://ecommons.luc.edu/meea

\section{Recommended Citation}

Yildirim-Karaman, Seçil, "Uncertainty in Financial Markets and Business Cycles". Topics in Middle Eastern and North African Economies, electronic journal, 19, 1, Middle East Economic Association and Loyola University Chicago, 2017, http://www.luc.edu/orgs/meea/

This Article is brought to you for free and open access by the Journals and Magazines at Loyola eCommons. It has been accepted for inclusion in Topics in Middle Eastern and North African Economies by an authorized administrator of Loyola eCommons. For more information, please contact ecommons@luc.edu. (c) (i) (2)

This work is licensed under a Creative Commons Attribution-Noncommercial-No Derivative Works 3.0 License. (C) 2017 The Authors 


\title{
Uncertainty in Financial Markets and Business Cycles
}

\author{
Seçil Yıldırım-Karaman ${ }^{1}$
}

\begin{abstract}
Can financial uncertainty shocks induce real downturns? To investigate this question theoretically, this paper develops a dynamic stochastic general equilibrium model with two period lived heterogenous agents, monopolistically competitive firms and sticky prices. In the model financial uncertainty is measured by the volatility of stock prices and this volatility results from the stochastic irrational beliefs of nonsophisticated agents about the future performance of the stock. An increase in the stock price volatility decreases aggregate demand and generates a significant contraction in output. The model contributes to the literature by modeling financial market volatility in a general equilibrium framework, establishing its causal impact on real variables, highlighting the mechanisms through which the impact works, and providing estimates of its magnitude.
\end{abstract}

Keywords: Financial Uncertainty; Volatility Shocks; DSGE; Business Cycles; Great Recession

JEL Classification: E12; E32; E37; G01; G12

${ }^{1}$ Department of Economics, Istanbul Kemerburgaz University, Istanbul, Turkey; secil.yildirim@kemerburgaz.edu.tr 


\section{Introduction}

This paper investigates whether uncertainty originating in financial markets affects real variables and helps drive business cycles. The impact of uncertainty is investigated based on a New Keynesian model with two types of agents, sophisticated and nonsophisticated, who price the risky asset, stock, differently. In the model, an increase in volatility of future stock price expectations of nonsophisticated agents increases the volatility of current stock prices. The stock price volatility, in turn, reduces consumption, investment, employment and output. The paper contributes to the literature by modeling financial market volatility in a general equilibrium framework, establishing its causal impact on real variables, highlighting the mechanisms through which the impact works, and providing estimates of its magnitude.

By investigating the real consequences of financial volatility, the paper fills a gap in the existing DSGE literature on business cycles. In the DSGE literature, the prevalent approach is to model volatility as originating from real sector. This modeling choice reflects the fact that modeling financial markets as an exogenous source of volatility is not straightforward when all agents are assumed to be rational. Hence, volatility is modeled as second moment shocks to the total factor productivity ${ }^{2}$, household discount rates $^{3}$, idiosyncratic productivity of the firms ${ }^{4}$, or fiscal policy tools. ${ }^{5}$ In these models an increase in real volatility in turn causes a contraction in output and induces endogenous volatility in asset prices.

The innovation in the current model is that it generates financial market volatility even in the absence of real shocks. In other words, in this model uncertainty shocks originate in the financial sector and are transmitted to real sector. The critical assumption for generating financial market volatility in the absence of real shocks is the existence of nonsophisticated agents in the model who are boundedly rational and have volatile expectations about future stock market performance. This modeling setup reflects the insight that financial markets might themselves be an independent source of uncertainty. Theoretically and empirically, there is a large body of work that suggests behavioral and informational shocks might lead financial volatility to increase over

\footnotetext{
2 See Bloom et al. (2012) and Basu and Bundick (2012).

3 See Basu and Bundick (2012).

4 See Gilchrist et al. (2014), Christiano et al. (2013), and Arellano et al. (2010).

5 See Fernandez-Villaverde et al. (2015).
} 
Topics in Middle Eastern and African Economies

Proceedings of Middle East Economic Association

Vol. 19, Issue No. 1, May 2017

and above volatility due to fundamental shocks. ${ }^{6}$ In this respect, this paper identifies a mechanism both for the exogenous increase in financial uncertainty caused by nonfundamental factors and its transmission to real industry. This independent impact of financial uncertainty might be working together with real uncertainty shocks emphasized in the literature and help understand the severity of the resulting downturns. This setup is particularly relevant for the recent Great Recession of 2008, considering the widespread consensus about the role of financial sector in instigating the crisis.

The paper formalizes the impact of financial uncertainty on real variables based on a model that works in two steps. The first step generates financial uncertainty as the outcome of "mood" shocks to agents. In particular, there are two types of agents, sophisticated and nonsophisticated, who price the risky asset, stock, differently. Sophisticated agents correctly discount future dividends. Nonsophisticated agents, on the other hand, are subject to "mood" shocks which change their level of "pessimism" about the future performance of the stock, and cause their valuation to deviate from sophisticated agents' valuation. The "mood" of nonsophisticated agents is subject to volatility shocks causing the volatility of the stock prices to be stochastic.

The second step in the model, the main focus of the paper, captures the impact of greater stock price volatility on real variables. The impact works as follows. First, because agents are risk averse, when future stock price volatility increases, demand for stocks and equilibrium stock price falls, and because agents hold stocks, there is a negative wealth shock. Second, the increase in stock price volatility implies an increase in volatility of future income, which induces agents to take precautionary measures. In response to both the wealth shock and precautionary motives, agents cut back on consumption and increase their labor supply. On the firm side, under the New Keynesian assumptions of monopolistic competition and sticky prices, lower wages increase markup, and higher markup contracts labor demand. Under plausible parameter values, labor demand contracts more than the increase in labor supply, and so equilibrium employment and output fall. All in all, the model generates a decline in equilibrium employment, consumption and output. However, the model does not capture the reduction in investments because agents tend to increase their savings which in turn increases investments.

${ }^{6}$ See De Long et al. (1990), Barberis et al. (1998), Baker and Wurgler (2006). 
Figure 1: Real GDP and Implied Volatility during the Great Recession

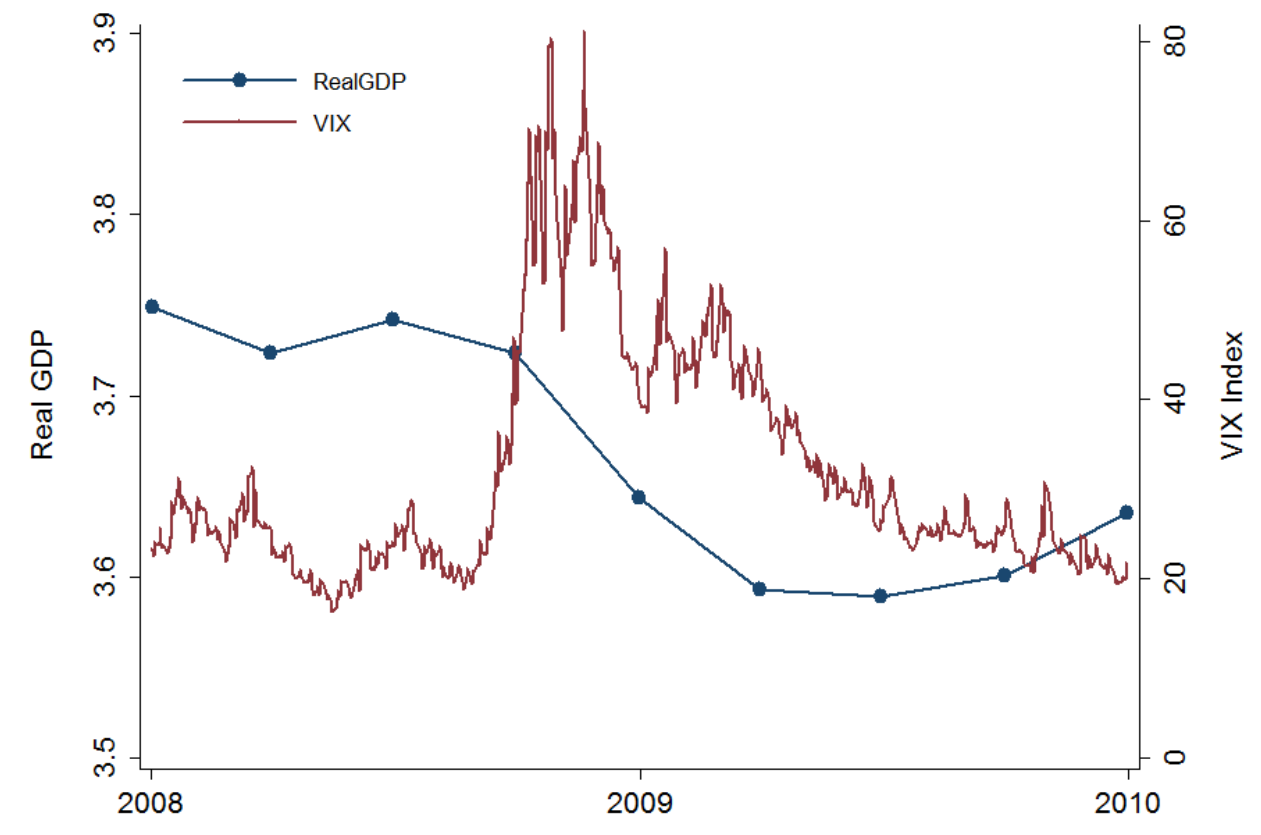

As Figure 1 demonstrates, the sequencing of events during the recent financial crises also provides evidence for the negative impact of financial market volatility on real production. In the build up to the Great Recession of 2008, a critical turning point was the collapse of Lehman Brothers. After Lehman failed, it created a widespread panic in financial markets about the possible bankruptcy of other financial institutions. The panic arguably increased the volatility in the financial markets, a feeling of uncertainty replaced economic optimism and this in turn played a role in the decision by consumers and firms to cut back their spending.

The rest of the paper proceeds as follows. Section 1 presents the model and section 2 describes the calibration procedure. Section 3 discusses the model assumptions and results, evaluates them and compares them with the empirical evidence. The last section concludes.

\section{The Model}


Topics in Middle Eastern and African Economies

Proceedings of Middle East Economic Association

Vol. 19, Issue No. 1, May 2017

\subsection{Agents}

Agents in the economy are modeled as an infinite sequence of overlapping generations (OLG). For simplicity, each generation has the same size and is assumed to live two periods. There are two types of young agents, sophisticated and nonsophisticated, which are assumed to be risk averse. The share of nonsophisticated and sophisticated agents are fixed and respectively denoted by $n$ and $1-n$ where $0<n<1$. They work, consume and save in the first period and retire in the second period. Their income in the second period is equal to the return on savings they made in the first period.

In the first period, the agents decide how much to work, how much to consume in the current period and save for the second period, and how to allocate savings between safe and risky assets to maximize their lifetime utility. The safe and risky assets are interpreted respectively as bonds and stocks. The price of the safe asset is always 1 in terms of the numeraire consumption good. Its one period return is known with certainty. The risky asset, stock, is supplied at a fixed amount and both the level and the volatility of its price are time varying and determined as discussed below.

Equilibrium asset pricing structure follows De Long et al. (1990) and stock price is determined by consolidating the portfolio choice decisions of both types of agents. The critical assumption in agents' problem is that the two types of agents price the risky assets, stocks, differently. The sophisticated agents correctly discount future dividends. The nonsophisticated agents, on the other hand, may be subject to "mood" shocks regarding the future performance of the stock, which in turn causes their valuation to deviate from sophisticated agents' valuation. In other words, nonsophisticated agents misperceive the expected stock price based on their irrational beliefs. These shocks to "mood" of nonsophisticated agents are modeled as a stochastic process and both their level and variance are assumed to follow $\operatorname{AR}(1)$ processes. In the following subsections both types of agents' problems are specified in more detail.

\subsubsection{Sophisticated agents}

Sophisticated agents maximize their lifetime utility: 


$$
\underset{N_{t}^{s}, S_{t}^{s}, \lambda_{t}^{s}}{\operatorname{ax}} U\left(C_{y, t}^{s}, N_{t}^{s}\right)+\beta E_{t}\left[U\left(C_{o, t+1}^{s}\right)\right]
$$

subject to:

$$
\begin{gathered}
\frac{W_{t}}{P_{t}} N_{t}^{s}=w_{t} N_{t}^{s}=S_{t}^{s}+C_{y, t}^{s} \\
S_{t}^{s}-B_{t}^{s}=\frac{\lambda_{t}^{s} P_{t}^{e}}{P_{t}}=\lambda_{t}^{s} p_{t}^{e} \\
E_{t}\left[C_{o, t+1}^{s}\right]=S_{t}^{s} r_{t}^{b}+\lambda_{t}^{s} E_{t}\left[\left(p_{t+1}^{e}+d_{t}\right)-r_{t}^{b} p_{t}^{e}\right]
\end{gathered}
$$

where $C_{y}^{s}$ and $C_{o}^{s}$ respectively represent the consumption of young and old sophisticated agents. $P$ is the price level and $w$ is the real wage level in the economy, $S^{s}$ is the amount of saving in terms of consumption goods which is allocated to stocks and bonds, $B$ and $\lambda^{s}$ are respectively the amount of bonds and stocks purchased by sophisticated agents. Price of one unit of bond is equal to one unit of consumption good. $p^{e}$ is the real price of one unit of stock, $r^{b}$ is the real return on the bond and $d$ is the real dividend payment for one unit of stock. In order to eliminate the uncertainty from future dividends in the agents problem, it is assumed that firms announce their dividends at time $t$ based on the their profits at time $t$ and distribute them at time $t+1$.

Utility function of the agents is defined as:

$$
\begin{gathered}
U\left(C_{y, t}, N_{t}\right)=-e^{-2 \gamma C_{y, t}}-v \frac{N_{t}^{1+\varphi}}{1+\varphi} \\
E_{t}\left[U\left(C_{o, t+1}\right)\right]=E_{t}\left[-e^{-2 \gamma C_{o, t+1}}\right]
\end{gathered}
$$

where $\gamma$ is the coefficient of absolute risk aversion and $1 / \varphi$ is the Frisch elasticity of labor supply.

Under the assumption of normally distributed returns, maximizing (6) is equivalent to 
maximizing:

$$
E_{t}\left[C_{o, t+1}\right]-\gamma \sigma_{c_{o, t+1}}^{2}
$$

Since the variance of consumption of old agents is a function of the variance of stock price, $\sigma_{c_{o, t+1}}^{2}=\left(\lambda_{t}^{s}\right)^{2} \sigma_{p_{t+1}^{e}}^{2}$, the expression (7) can be rewritten as:

$$
E_{t}\left[C_{o, t+1}\right]-\gamma\left(\lambda_{t}^{s}\right)^{2} \sigma_{p_{t+1}^{e}}^{2}
$$

Sophisticated agents choose how much to work, how much to save and how to allocate their savings between risky and riskless assets. First order conditions for the utility maximization problem of sophisticated agents are:

$$
\begin{gathered}
U^{\prime}\left(C_{y, t}^{s}\right)=E_{t}\left[\beta r_{t}^{b} U^{\prime}\left(C_{o, t+1}^{s}\right)\right] \\
\lambda_{t}^{s}=E_{t}\left[\frac{\left(p_{t+1}^{e}+d_{t}\right)-r_{t}^{b} p_{t}^{e}}{2 \gamma \sigma_{p_{t+1}^{e}}^{2}}\right] \\
U^{\prime}\left(C_{y, t}^{s}\right) w_{t}=-U^{\prime}\left(N_{t}^{s}\right)
\end{gathered}
$$

where (9) is the Euler equation, (10) is the demand function of the sophisticated agents for the risky asset and (11) is the labor supply function.

\subsubsection{Nonsophisticated agents}

The young nonsophisticated agents' optimization problem at period $t$ is:

$$
\underset{N_{t}^{n}, S_{t}^{n}, \lambda_{t}^{n}}{\operatorname{Uax}} U\left(C_{y, t}^{n}, N_{t}^{n}\right)+\beta E_{t}\left[U\left(C_{o, t+1}^{n}\right)\right]
$$

subject to: 


$$
\begin{gathered}
\frac{W_{t}}{P_{t}} N_{t}^{n}=w_{t} N_{t}^{n}=S_{t}^{n}+C_{y, t}^{n} \\
S_{t}^{n}-B_{t}^{n}=\frac{\lambda_{t}^{n} P_{t}^{e}}{P_{t}}=\lambda_{t}^{n} p_{t}^{e} \\
E_{t}\left[C_{o, t+1}^{n}\right]=S_{t}^{n} r_{t}^{b}+\lambda_{t}^{n} E_{t}\left[p_{t+1}^{e}+d_{t}-a_{t}-r_{t}^{b} p_{t}^{e}\right]
\end{gathered}
$$

Note that the only difference between the nonsophisticated and sophisticated agents problem is that the former has an extra term, $a$, in the budget constraint (15). $a$ captures the nonsophisticated agents mood, and more specifically, their degree of pessimism about the future performance of the stock. If the level of $a$ increases, nonsophisticated agents become more pessimistic about the expected value of their savings. If the volatility of $a$ increases, volatility of the expected future value of their savings increases. $a$ is assumed to be stochastic and both its level and volatility are assumed to follow AR(1) processes:

$$
\begin{gathered}
a_{t}=\rho_{a} a_{t-1}+\sigma_{t}^{a} \varepsilon_{t}^{a} \\
\sigma_{t}^{a}=\left(1-\rho_{\sigma^{a}}\right) \sigma^{a}+\rho_{\sigma^{a}} \sigma_{t-1}^{a}+\sigma^{\sigma^{a}} \varepsilon_{t}^{\sigma^{a}}
\end{gathered}
$$

where $\rho_{a}<1, \rho_{\sigma^{a}}<1$.

In the model, level shocks to mood of nonsophisticated agents are given by the increasing value of $\varepsilon^{a}$ in equation (16). Such a shock increases $a$, makes nonsophisticated agents more pessimistic and in turn depresses stock price. Volatility shocks to the mood of nonsophisticated agents are given by the increasing value of $\varepsilon^{\sigma^{a}}$ in equation (17). These volatility shocks in turn increase the volatility of stock prices. Hence, volatility shocks to nonsophisticated agents mood translate into volatility shocks to financial markets and the model investigates how these shocks in turn affect real variables.

The first order conditions that follow are: 


$$
\begin{gathered}
U^{\prime}\left(C_{y, t}^{n}\right)=E_{t}\left[\beta r_{t}^{b} U^{\prime}\left(C_{o, t+1}^{n}\right)\right] \\
\lambda_{t}^{n}=E_{t}\left[\frac{\left(p_{t+1}^{e}+d_{t}-a_{t}\right)-r_{t}^{b} p_{t}^{e}}{2 \gamma \sigma_{p_{t+1}^{e}}^{e}}\right] \\
U^{\prime}\left(C_{y, t}^{n}\right) w_{t}=-U^{\prime}\left(N_{t}^{n}\right)
\end{gathered}
$$

where (18) is the Euler equation, (19) is the demand function of the nonsophisticated agents for the risky asset and (20) is the labor supply function.

When we consolidate equations (9) and (18) with the weights of sophisticated and nonsophisticated agents we obtain the consolidated Euler equation:

$$
e^{-2 \gamma C_{y, t}}=E_{t}\left\lfloor\beta r_{t}^{b} e^{-2 \gamma C_{o, t+1}}\right\rfloor
$$

where $C_{y, t}$ is the total consumption of young in period $t$.

$$
C_{y, t}=(1-n) C_{y, t}^{s}+n C_{y, t}^{n}
$$

$C_{o, t}$ is the total consumption of old in period $t$.

$$
C_{o, t}=(1-n) C_{o, t}^{s}+n C_{o, t}^{n}
$$

Similarly, we combine equations (11) and (20) to obtain the consolidated labor supply function. Total labor hours supplied is equal to:

$$
N_{t}=(1-n) N_{t}^{s}+n N_{t}^{n}
$$

\subsubsection{Equilibrium asset pricing}

The equilibrium price of the risky asset is determined by setting demand for stocks equal to the supply. The supply of stocks is fixed at $S^{e}$ which is normalized to one. It follows that the stock price is determined by setting the total demand of both types of agents equal to one: 


$$
(1-n) \lambda_{t}^{s}+n \lambda_{t}^{n}=S^{e}=1
$$

Equations (10), (19) and (25) determine the evolution of the stock price:

$$
p_{t}^{e}=1 / r_{t}^{b} E_{t}\left[\left(p_{t+1}^{e}+d_{t}\right)-2 \gamma \sigma_{p_{t+1}^{e}}^{2}-n a_{t}\right]
$$

Through forward iteration of equation (26), we can define the variance of the stock price as a function of the variance of the nonsophisticated agents' mood. Discounting the expected future variances with the steady state discount factor, equation (26) can be written as:

$$
p_{t}^{e}=1 / r_{t}^{b} E_{t}\left[\left(p_{t+1}^{e}+d_{t}\right)-2 \gamma\left[\left(\rho_{a}^{2} \operatorname{Var}\left(a_{t}\right)+E_{t}\left[\left(\sigma_{t+1}^{a}\right)^{2}\right]\right) \frac{n^{2}}{\left(r_{s s}^{b}-\rho_{a}\right)^{2}}\right]-n a_{t}\right]
$$

From equation (27), we can make two immediate observations. First, stock prices persistently deviate from their fundamental values. The intuition is that because the agents are risk averse the additional risk generated by the unpredictable mood of the nonsophisticated agents can not be eliminated completely. Hence, arbitrage trading stays limited. Second, an increase in both the volatility and the level of the pessimistic beliefs of nonsophisticated agents have a negative impact on stock prices. An increase in the level of pessimistic beliefs decreases only the demand of nonsophisticated agents. An increase in the volatility of misperception, however, decreases the demand of both types of agents.

\subsection{Firms}

There are two types of firms in the model, intermediate and final goods producers.

\subsubsection{Intermediate goods producers}

Intermediate goods producers are monopolistically competitive and face a quadratic cost of changing their price $P_{t}(i)$ each period. Each firm $i$ produces $Y_{t}(i)$ using capital $K_{t}(i)$ and labor $N_{t}(i)$. They use debt and equity to finance their investment and face a quadratic cost for adjusting the investment rate. Each firm $i$ chooses its price level, investment and labor demand to maximize the discounted sum of the equity value. All intermediate goods firms have CobbDouglas production function with constant returns to scale and a fixed cost $f c$. Hence, firms 
maximize:

$$
\underset{K_{t+1}, I_{t}, P_{t}, N_{t}}{\operatorname{Max}}\left[\sum_{s=0}^{\infty} M_{t+s}\left[\frac{D_{t+s}(i)}{P_{t+s}(i)}\right]\right]
$$

subject to:

$$
\begin{gathered}
Y_{t}(i)=\left[\frac{P_{t}(i)}{P_{t}}\right]^{-\theta} Y_{t}=z K_{t}^{\alpha}(i) N_{t}^{1-\alpha}(i)-f_{c} \\
I_{t}(i)=K_{t+1}(i)-\left(1-\delta-\frac{\psi_{k}}{2}\left(\frac{I_{t}(i)}{K_{t}(i)}-\delta\right)^{2}\right) K_{t}(i) \\
\frac{D_{t}(i)}{P_{t}(i)}=d_{t}(i)=\left[\frac{P_{t}(i)}{P_{t}}\right]^{1-\theta} Y_{t}-I_{t}(i)-w_{t} N_{t}(i)-r_{t-1}^{b} B_{t-1} \\
+B_{t}-\frac{\psi_{p}}{2}\left(\frac{P_{t}(i)}{P_{t-1}(i)}-1\right)^{2} Y_{t}
\end{gathered}
$$

where constraint (29) states that total production of intermediate good $i$ must be equal to the total demand of final goods producers for intermediate good $i$. Since intermediate goods producers have monopoly power, they take the demand function as given when they solve their optimization problem. Constraint (30) represents the capital accumulation process and constraint (31) captures that the profit of the firm $i$ is distributed to the equity holders as dividend payments.

First order condition with respect to $N_{t}$ gives the labor demand function:

$$
w_{t}=(1-\alpha) z \mu_{t} K_{t}^{\alpha}(i) N_{t}^{-\alpha}(i)
$$

where $\mu_{t}$ is the Lagrange multiplier for constraint (29) and can be interpreted as marginal cost of producing the intermediate good and $1 / \mu_{t}$ is the mark-up at time $t$.

First order condition with respect to $K_{t+1}$ gives investment demand equation: 


$$
q_{t}=E_{t}\left[M_{t+1}\left[\alpha z \mu_{t+1} K_{t+1}^{\alpha-1}(i) N_{t+1}^{1-\alpha}(i)+q_{t+1}\left(\begin{array}{c}
1-\delta-\frac{\psi_{k}}{2}\left(\frac{I_{t+1}(i)}{K_{t+1}(i)}-\delta\right)^{2} \\
\left.+\psi_{k}\left(\frac{I_{t+1}(i)}{K_{t+1}(i)}-\delta\right)\left(\frac{I_{t+1}(i)}{K_{t+1}(i)}\right)\right)
\end{array}\right]\right]\right.
$$

where $q_{t}$ is the Lagrange multiplier for constraint (30) and can be interpreted as the price of a marginal unit of capital.

First order condition with respect to $I_{t}$ is:

$$
1-\psi_{k}\left(\frac{I_{t}(i)}{K_{t}(i)}-\delta\right)=\frac{1}{q_{t}}
$$

First order condition with respect to $P_{t}(i)$ is:

$$
\psi_{p}\left(\frac{P_{t}(i)}{P_{t-1}(i)}-1\right)\left(\frac{P_{t}}{P_{t-1}(i)}\right)=\left(\begin{array}{c}
(1-\theta)\left[\frac{P_{t}(i)}{P_{t}}\right]^{-\theta}+\theta \mu_{t}\left[\frac{P_{t}(i)}{P_{t}}\right]^{-\theta-1} \\
+\psi_{p} E_{t}\left[M_{t+1} \frac{Y_{t+1}}{Y_{t}}\left(\frac{P_{t+1}(i)}{P_{t}(i)}-1\right)\left(\frac{P_{t+1}(i)}{P_{t}(i)} \frac{P_{t}}{P_{t}(i)}\right)\right]
\end{array}\right)
$$

First order condition with respect to $B_{t}(i)$ is:

$$
1 / r_{t}^{b}=M_{t+1}
$$

Since Modigliani and Miller Theorem (Modigliani and Miller (1959)) holds in this set up, debt financing and equity financing are equivalent for the firm. Without loss of generality, it is assumed that intermediate goods producers' borrowing is equal to a fixed share of the value of capital:

$$
B_{t}=\tau q_{t} K_{t}
$$

\subsubsection{Final goods producers}

Final goods producers use the intermediate goods as input, have a constant returns to scale 
technology and operate in a perfectly competitive market. The representative final goods producer maximizes its profits:

$$
P_{t} Y_{t}-\int_{0}^{1} P_{t}(i) Y_{t}(i) d i
$$

subject to:

$$
Y_{t}=\left[\int_{0}^{1} Y_{t}(i)^{\frac{\theta-1}{\theta}} d i\right]^{\frac{\theta-1}{\theta}}
$$

where $\theta$ is the elasticity of substitution between intermediate goods.

First order condition gives the demand function for each intermediate good $i$ :

$$
Y_{t}(i)=Y_{t}\left[\frac{P_{t}(i)}{P_{t}}\right]^{-\theta}
$$

\subsection{Monetary Policy}

It is assumed that monetary authority controls the nominal interest rates to stabilize the economy. Following Basu and Bundick (2012) the monetary authority adjusts the nominal interest rates using the following rule:

$$
\ln r_{t}=\rho_{r} \ln r_{t-1}+\left(1-\rho_{r}\right)\left(\ln r+\rho_{\pi} \ln \pi_{t}+\rho_{y} \ln \frac{Y_{t}}{Y_{t-1}}\right)
$$

Fisher equation gives the relationship between the real interest rate, expected inflation and the nominal interest rate.

$$
\frac{r_{t}}{r_{t}^{b}}=E_{t}\left[\pi_{t+1}\right]
$$

So, the Euler equation becomes:

$$
e^{-2 \gamma_{y, t}}=E_{t}\left[\beta \frac{r_{t}}{\pi_{t+1}} e^{-2 \gamma C_{0, t+1}}\right]
$$




\subsection{Equilibrium Conditions}

Total consumption in period $\mathrm{t}$ is equal to the summation of the consumptions of young and old agents in period $t$ :

$$
C_{t}=C_{y, t}+C_{o, t}
$$

Goods market equilibrium implies that total output (net of inflation cost) has to be either consumed or invested:

$$
Y_{t}-\frac{\psi_{p}}{2}\left(\frac{P_{t}(i)}{P_{t-1}(i)}-1\right)^{2} Y_{t}=C_{t}+I_{t}
$$

Labor supply equation and labor demand equation together give the labor market equilibrium:

$$
N_{t}=\left(\frac{(1-\alpha) z \mu_{t} \lambda_{t} K_{t}^{\alpha}}{v}\right)^{1 /(\varphi+\alpha)}
$$

All firms choose the same price $P_{t}(i)=P_{t}$, capital $K_{t}(i)=K_{t}$ and labor $N_{t}(i)=N_{t}$. Inflation is defined as $\pi_{t}=\frac{P_{t}}{P_{t-1}}$.

\subsection{Solution Method}

Perturbation AIM algorithm developed by Swanson et al. (2006) is used to solve the model. This algorithm uses $n t h$ order Taylor approximation around the steady state to find the rational expectations solution of the model.

In order to investigate the independent effects of the second moment shocks, third order approximation is made around the nonstochastic steady state of the model along the lines of Basu and Bundick (2012) and Fernandez-villaverde et al. (2011). Consequently, impulse responses of variables to one standard deviation increase in the financial volatility are estimated in terms of log deviations from their ergodic means. 


\section{Calibration}

To analyze the quantitative impact of financial volatility shocks, I calibrate the model at quarterly frequency. Some of the parameters are backed out from the data by matching model generated moments with those in the actual data. Others are based on standard values used in the literature. The resulting parameter set is summarized in Table (1).

In the first step of the calibration of the uncertainty shock process, I characterize the financial volatility in the actual data. The proxy for financial volatility I use is Chicago Board Options Exchange Volatility Index (VIX). The VIX is a measure of the expected volatility of the Standard and Poor's 500 stock index, and is the standard proxy of forward-looking financial volatility used in the literature. The VIX is available daily, so I first take the quarterly averages of the index between 1990 and 2014 to match the frequency of the model. The resulting quarterly VIX series has a sample average of $21.01 \%$. I then estimate the following reduced-form autoregressive time series model:

$$
V I X_{t}=\left(1-\rho_{v i x}\right) V I X_{s s}+\rho_{v i x} V I X_{t-1}+\sigma^{v i x} \varepsilon_{t}
$$

The estimated persistence parameter $\rho_{v i x}$ and the standard deviation of the disturbance $\sigma_{t}^{v i x}$ are respectively 0.73 and 5.01 . Hence, one standard deviation shock to VIX increases the level of VIX from its sample average of $21.01 \%$ to $26.02 \%$, or by about a quarter.

The second step is to derive a model generated counterpart to VIX and match its moments with the moments of actual VIX index to back out the parameters of the model. The model-implied VIX index I use is the expected conditional volatility of the expected return on the equity of the representative intermediate-goods producing firm. Following Basu and Bundick (2012), the model implied VIX is:

$$
V I X_{t}^{i m p}=100 \sqrt{4 \operatorname{Var}_{t}\left[E_{t}\left(R_{t+1}^{e q}\right)\right]}
$$

where $\operatorname{Var}_{t}\left[E_{t}\left(R_{t+1}^{e q}\right)\right]$ is the quarterly conditional variance of the expected equity return. Setting the steady state value of model implied VIX equal to its sample mean of $21.01 \%$, the share of nonsophisticated agents $(n)$ is backed out as $14.67 \%$. Similarly, I set the uncertainty 
shock parameter $\sigma^{\sigma^{a}}$ as 0.0074 so that one standard deviation shock to the volatility of degree of misperception increases the model implied VIX by a quarter as in actual data. Finally, I calibrate the persistence parameter for the uncertainty shock process, $\rho_{\sigma^{a}}$, as 0.73 which is the estimated value of the persistence parameter in the autoregressive process (52).

Persistence parameter for the level shock is calibrated using S\&P 500 series. Since the series is non-stationary, first it is decomposed into trend and cycle components using HodrickPrescott filter, and then persistence parameter of $\mathrm{AR}(1)$ process for the cyclical component is estimated. The persistence parameter is found to be 0.88 and is significant at $1 \%$.

Other parameters are determined as follows. Calibration of adjustment cost to change the price level, $\psi_{p}$, is based on Ireland (2003) and calibrated as 160 . Adjustment cost for investment, $\psi_{k}$, is based on Basu and Bundick (2012), In particular, adjustment cost parameter is calibrated so that the elasticity of investment to capital ratio with respect to marginal cost of capital is 2 . Frisch elasticity of labor supply is equal to $1 / \varphi$ and assumed to be $1 . v$, labor supply constant, is calibrated so that the steady state fraction of time spent in employment is $40 \%$ of the one unit of time endowment.

Table 1: Calibrated Parameters

\begin{tabular}{|c|c|c|}
\hline Parameter & Value & Definition \\
\hline$\alpha$ & 0.33 & Share of capital in the production \\
\hline$\beta$ & 0.98 & Subjective discount rate \\
\hline$\delta$ & 0.025 & Depreciation rate \\
\hline$z$ & 0.95 & Solow residual \\
\hline$\psi_{p}$ & 5 & Elasticity of substitution between intermediate goods \\
\hline$\psi_{k}$ & 160 & Adjustment cost to change price level \\
\hline$\rho_{a}$ & 0,88 & Adjustment cost to change investment \\
\hline$\sigma^{a}$ & 0,01 & Persistence of first moment financial shock \\
\hline$\rho_{\sigma^{a}}$ & 0,73 & Persistence of second moment financial shock \\
\hline$\sigma^{\sigma^{a}}$ & 0.0074 & Volatility of second moment financial shock \\
\hline$\gamma$ & 2 & Degree of risk aversion \\
\hline$\varphi$ & 1 & Inverse of elasticity of labor supply \\
\hline$v$ & 4.35 & Labor supply constant \\
\hline
\end{tabular}




\begin{tabular}{|c|c|c|}
\hline$n$ & 0.1467 & Share of nonsophisticated traders \\
\hline$\rho_{\pi}$ & 1.5 & Sensitivity of nominal interest rate to changes in inflation \\
\hline
\end{tabular}

\section{Results and Interpretation}

This section reviews and interprets the findings of the model. The first subsection discusses the mechanisms through which financial uncertainty affects real variables and puts them in the context of existing literature. The second subsection presents the impulse response functions to financial volatility shocks and investigates the quantitative impact of the shocks based on evidence from the Great Recession. The third subsection interprets the model's treatment of financial markets. The last subsection evaluates the performance of the model by comparing its predictions regarding comovements and magnitudes of variables with the actual data.

\subsection{Modeling the Impact of Financial Market Volatility on Real Variables}

In the model, an increase in the volatility of stock prices alters the agents' incentives in two ways. First, when stock price volatility increases, stock price falls, and consequently there is an immediate negative wealth shock to the agents. Second, higher stock price volatility increases the volatility of agents' future income, and because agents are risk averse, it creates incentives for precautionary measures. Both of these channels induce the agents to cut back on consumption and increase their savings and labor supply. On the firm side, with monopolistic competition and sticky prices, falling wages increase markup, which in turn depresses labor demand. Under plausible parameter values, the decline in firms' labor demand exceeds the increase in workers' labor supply, and equilibrium wage and employment fall. In equilibrium, consumption, employment and output decrease. The model generates an increase in the investments due to the increase in the precautionary savings.

The paper that the current model relates most closely to is Basu and Bundick (2012), which also investigates the impact of uncertainty on real variables in a New Keynesian setup. There is, however, an important difference. In the current study, the source of uncertainty is financial markets, whereas in Basu and Bundick (2012), household discount rates and total factor 
productivity. Consequently, while in both models uncertainty shocks depress output through precautionary increases in labor supply and saving, in the current model, there is a second channel which is absent from Basu and Bundick (2012). In particular, in the current model, an increase in the volatility of future stock prices induce an immediate fall in the current stock prices, which acts as a negative wealth shock and exacerbates the negative impact on output.

\subsection{Quantitative Impact of Volatility Shocks and the Great Recession}

In this section I use the simulation results to graphically demonstrate the mechanisms through which the impact of financial uncertainty works and provide estimates of the magnitude of the impact.

Figure (2) displays the impact of one standard deviation increase in the financial volatility on the labor market for the parameter set in Table (1). As discussed above, the behavior of labor market is different when the prices are sticky. Labor supply shifts out due to the increase in the precautionary motives, but labor demand contracts more, so equilibrium employment and wage fall.

Figure 2: Labor Market Equilibrium before and after the Volatility Shock

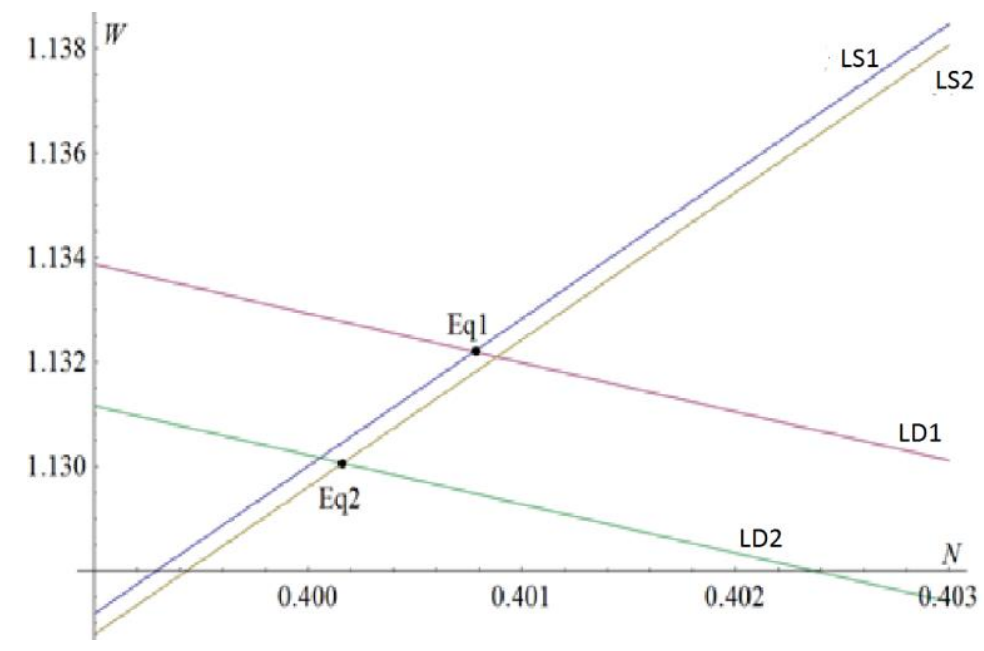

Figure 3: Impulse Responses to One Standard Deviation Financial Volatility Shock When the Prices are Sticky 


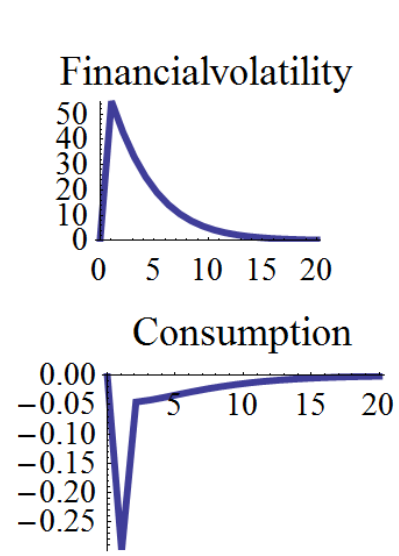

Hours

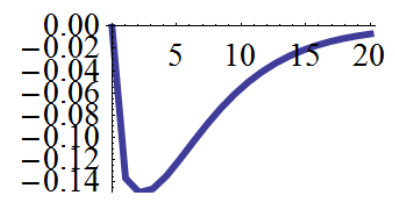

Realoutput

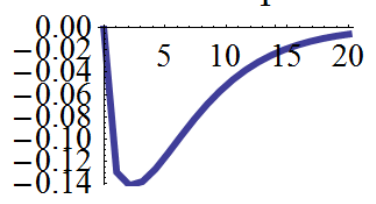

$\operatorname{eps}(\operatorname{VOLA})(t)$
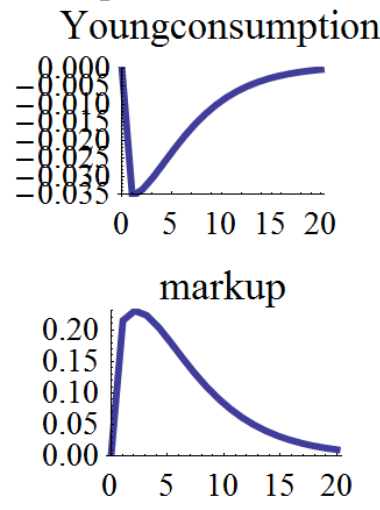

Impvix

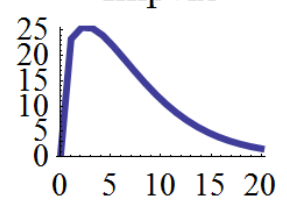

Inflation

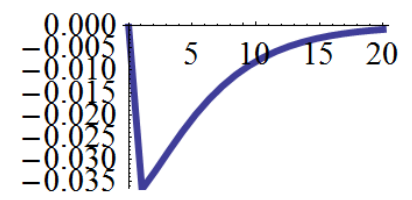

Oldconsumption
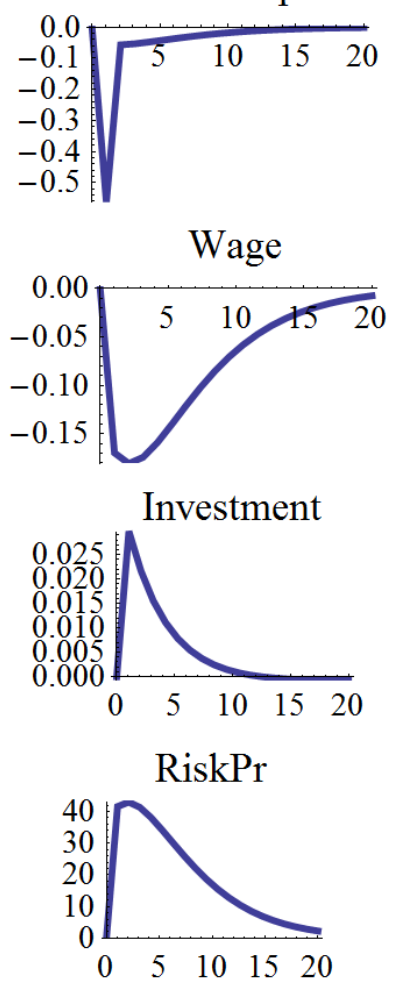

Figure (3) traces the impulse response functions of the real variables to the one standard deviation volatility shock to the degree of misperception of the nonsophisticated agents on a quarterly basis. One standard deviation increase in the volatility increases the model implied VIX by $25 \%$ compared to its ergodic mean as we observe in data. Consistent with the empirical evidence on recessions, the volatility shock is accompanied by fall in real output and its components. In particular, one standard deviation increase in volatility generates a $0.15 \%$ reduction in hours worked, $0.14 \%$ reduction in output, $0.25 \%$ reduction in consumption. The model also predicts a significant increase in the equity risk premium which is consistent with the evidence from the great recession.

Figure 4: VIX Implied Uncertainty Shocks 


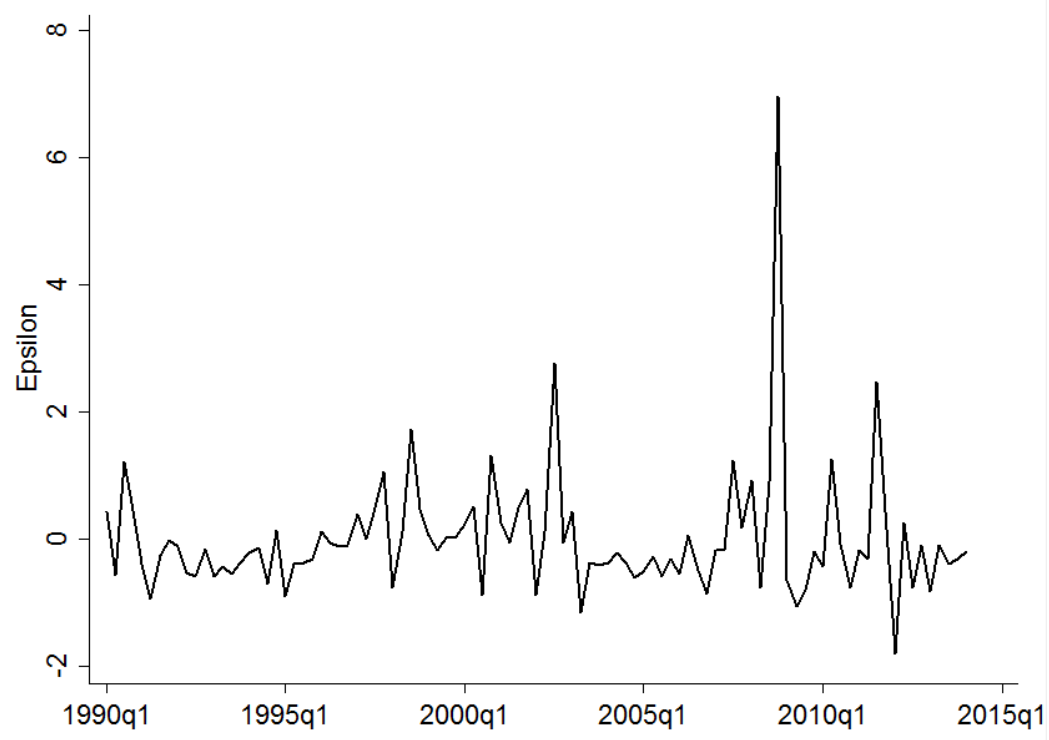

To put these magnitudes in context, I next turn to evidence from the Great Recession. Figure (4) shows the VIX-implied volatility shocks, calculated by dividing the residuals of autoregressive process (52) by its standard deviation. It shows that the increase in the VIX index during the Great Recession was approximately 6.5 standard deviations. Hence, to estimate the real impact of financial volatility during the Great Recession, the responses of real variables in Figure (3) should be multiplied by 6.5 . Table (2) summarizes the resulting estimates of quarterly changes in real variables. The model estimates a $0.91 \%$ peak drop in output, a $0.98 \%$ peak drop in working hours and a $1.6 \%$ peak drop in consumption. To put these estimates in context, in the first quarter of 2009, the output gap was $-6.2 \% .^{7}$ Because the model abstracts away from the fundamental shocks that were at work during the Great Recession, the numbers are not comparable per se, but the findings of the model suggest that roughly $15 \%$ of the gap can be attributed to the increase in the financial volatility which is a substantial impact.

Table 2: Simulation Results for the Great Recession

\begin{tabular}{|c|c|}
\hline & Peak Drops \\
\hline Output & $0.91 \%$ \\
\hline Working hours & $0.98 \%$ \\
\hline Consumption & $1.6 \%$ \\
\hline
\end{tabular}

\footnotetext{
7 Congressional Budget Office estimates.
} 


\subsection{Modeling Financial Market Volatility}

In the model, uncertainty in financial markets is generated by shocks to the "mood" of the nonsophisticated agents. In this respect, the model follows a long line of literature that goes back to Keynes (1936) and argues that markets can fluctuate under the influence of investors' animal spirits. According to this literature, due to behavioral biases, investors may misprice assets and asset prices may diverge from their fundamental values. ${ }^{8}$ There is growing consensus in the literature that the mood shocks play a significant role in financial markets, evidenced by the stock market bubbles and excess volatility in aggregate stock index returns that can not be explained by volatility in fundamentals. ${ }^{9}$

Note, however, that the main question that this paper investigates is how exogenous volatility in financial markets impact real variables. In this respect, in the broader interpretation of the model, the mood shocks can be considered as an analytical device to generate the exogenous volatility in financial markets in order to trace its impact. Financial markets may become more volatile for reasons other than mood shocks, and the findings of the paper regarding the mechanisms through which financial volatility affects output would still be valid.

A critical aspect of the financial markets in the model is that the stock prices deviate from their fundamental values. The rationale behind this deviation might not be immediately transparent, as the efficient market hypothesis argues that even if non-sophisticated traders exist and deviate the prices from their fundamental values, existence of rational arbitrageurs should drive prices towards their fundamental values. ${ }^{10}$ However, when the mood of the nonsophisticated traders is unpredictable, arbitrage trading charges additional risk to the arbitrageur. If the arbitrageur is risk averse then arbitrage becomes limited and fails to eliminate the deviations of asset prices from their fundamental values completely. Hence, under limited arbitrage these deviations can be persistent even if there is no fundamental risk. ${ }^{11}$

Implicit in the model is also a particular explanation to the equity premium puzzle. According to the model, the equity risk premium is higher than what is justified by the

\footnotetext{
8 See De Long et al. (1990), Barberis et al. (1998).

9 See Baker and Wurgler (2006).

10 See Fama (1965), Sharpe (1964), Ross (1976).

11 See De Long et al. (1990) and Barberis et al. (1998).
} 
fundamentals, because the volatility of the mood of the nonsophisticated investors introduces additional stock price volatility. Assuming an absolute risk aversion parameter of 2 , the model generates an ergodic mean of $4 \times 1.06 \%=4.28 \%$ for the equity risk premium. This estimate is very close to the actual average value of the equity risk premium for the years between 1962 and 2011 which is $5.38 \% .^{12}$

\section{Conclusion}

This paper investigates whether an increase in uncertainty in financial markets helps drive business cycles. While the financial consequences of real volatility shocks has been modeled extensively, the real consequences of financial volatility shocks have received less attention. The Great Recession, however, suggests that financial volatility may independently contribute to the severity of economic downturns. The paper investigates this impact by a model at the intersection of the literatures on equilibrium asset pricing under the noise trading risk and DSGE models with monopolistically competitive firms and sticky prices. The results of the model suggest that the negative impact of financial volatility on output works by contracting aggregate demand and the simulation results suggest this impact is substantial.

\section{References}

Arellano, C., Bai, Y., Kehoe, P., 2010. Financial markets and uctuations in uncertainty. Federal Reserve Bank of Minneapolis Working Paper.

Baker, M., Wurgler, J., 2006. Investor sentiment and the cross-section of stock returns. The Journal of Finance 61 (4), 1645-1680.

Barberis, N., Shleifer, A., Vishny, R., 1998. A model of investor sentiment. Journal of Financial Economics 49 (3), 307-343.

12 See Damodaran (2013). 
Basu, S., Bundick, B., 2012. Uncertainty shocks in a model of effective demand. National Bureau of Economic Research.

Bloom, N., Floetotto, M., Jaimovich, N., Saporta-Eksten, I., Terry, S. J., 2012. Really uncertain business cycles. National Bureau of Economic Research.

Christiano, L., Motto, R., Rostagno, M., 2013. Risk shocks. National Bureau of Economic Research.

Damodaran, A., 2013. Equity risk premiums (erp): Determinants, estimation and Implications the 2013 edition.

De Long, J. B., Shleifer, A., Summers, L. H., Waldmann, R. J., 1990. Noise trader risk in financial markets. Journal of political Economy, 703-738.

Fama, E. F., 1965. The behavior of stock-market prices. Journal of business, 34-105.

Fernandez-Villaverde, J., Guerron-Quintana, P., Kuester, K., Rubio-Ramirez, J., 2015. Fiscal volatility shocks and economic activity. American Economic Review 105 (11), 33523384.

Fernandez-villaverde, J., Guerron-quintana, P., Rubio-ramirez, J. F., Uribe, M., 2011. Risk matters: The real effects of volatility shocks. American Economic Review 101 (6).

Gilchrist, S., Sim, J. W., Zakrajsek, E., 2014. Uncertainty, financial frictions, and investment dynamics. National Bureau of Economic Research.

Keynes, J. M., 1936. The general theory of employment, interest, and money.

Modigliani, F., Miller, M. H., 1959. The cost of capital, corporation finance, and the theory of investment. American Economic Review 49 (4), 655-669.

Ross, S. A., 1976. The arbitrage theory of capital asset pricing. Journal of Economic Theory 13 (3), 341-360.

Sharpe, W. F., 1964. Capital asset prices: A theory of market equilibrium under conditions of risk. The Journal of Finance 19 (3), 425-442.

Swanson, E. T., Anderson, G. S., Levin, A. T., 2006. Higher-order perturbation solutions to dynamic, discrete-time rational expectations models. Federal Reserve Bank of San Francisco Working Paper Series 1. 